\title{
Large measles outbreak introduced by asylum seekers and spread among the insufficiently vaccinated resident population, Berlin, October 2014 to August 2015
}

\author{
D Werber ${ }^{12}$, A Hoffmann ${ }^{1234}$, S Santibanez 5 , A Mankertz 5 , D Sagebiel 1 \\ 1. State Office for Health and Social Affairs, Berlin, Germany \\ 2. These authors contributed equally to this work \\ 3. Postgraduate Training for Applied Epidemiology (PAE), Robert Koch Institute, Berlin, Germany \\ 4. European Programme for Intervention Epidemiology Training (EPIET), European Centre for Disease Prevention and Control \\ (ECDC), Stockholm, Sweden \\ 5. National Reference Center for Measles, Mumps, Rubella, Robert Koch Institute, Berlin, Germany
}

Correspondence: Dirk Werber (dirk.werber@lageso.berlin.de)

Citation style for this article:

Werber D, Hoffmann A, Santibanez S, Mankertz A, Sagebiel D. Large measles outbreak introduced by asylum seekers and spread among the insufficiently vaccinated resident population, Berlin, October 2014 to August 2015. Euro Surveill. 2017;22(34):pii=30599. DOI: http://dx.doi.org/10.2807/1560-7917.

ES.2017.22.34.30599

Article submitted on 23 September 2016 / accepted on 18 February 2017 / published on 24 August 2017

The largest measles outbreak in Berlin since 2001 occurred from October 2014 to August 2015. Overall, 1,344 cases were ascertained, $86 \%$ (with available information) unvaccinated, including 146 (12\%) asylum seekers. Median age was 17 years (interquartile range: 4-29 years), 26\% were hospitalised and a 1-yearold child died. Measles virus genotyping uniformly revealed the variant 'D8-Rostov-Don' and descendants. The virus was likely introduced by and initially spread among asylum seekers before affecting Berlin's resident population. Among Berlin residents, the highest incidence was in children aged $<2$ years, yet most cases (52\%) were adults. Post-exposure vaccinations in homes for asylum seekers, not always conducted, occurred later (median: 7.5 days) than the recommended 72 hours after onset of the first case and reached only half of potential contacts. Asylum seekers should not only have non-discriminatory, equitable access to vaccination, they also need to be offered measles vaccination in a timely fashion, i.e. immediately upon arrival in the receiving country. Supplementary immunisation activities targeting the resident population, particularly adults, are urgently needed in Berlin.

\section{Introduction}

Measles is a highly communicable viral disease causing substantial morbidity and mortality globally, mostly in low-income countries [1]. Vaccination can safely and effectively prevent measles disease and measles virus (MV)-induced immunosuppression, thereby also preventing all-cause secondary infectious diseases [2]. The World Health Organization (WHO) has targeted measles and rubella for Regional elimination, and Germany has committed to this goal [3]. The key strategy for elimination is to achieve and sustain a population coverage of $\geq 95 \%$ with two doses of a MV-containing vaccine $[4,5]$. Thus far, elimination has only been reached in the Americas $[6,7]$. The WHO European Region failed to achieve the target date for elimination in 2015 [8].

In Germany, immunisation is voluntary and the German Standing Committee on Vaccination (STIKO) recommends routine administration of two doses of measles vaccine, at 11-14 and 15-23 months of age [9]. Although vaccine coverage for measles has increased substantially in children at school entry (5- to 6-year-olds) in the last decade, it is still below the $95 \%$ target $(93 \%$ in Germany for two doses of measles in $2014 ; 92 \%$ in Berlin) [10]. Since 2010, STIKO has additionally recommended measles vaccination for adults born after 1970 with incomplete or unknown vaccination status [11].

The European Union has recently experienced a very large influx of asylum seekers with more than 600,000 and 1.3 million registered first-time applicants in 2014 and 2015, respectively [12]; Germany had the largest number of applicants. In Berlin, a city with 3.5 million inhabitants [13], 12,079 asylum seekers (12\% from Bosnia and Herzegovina) were registered in 2014. This number more than tripled in $2015(n=44,615)$, with a steep increase in the second half of the year. Refugees and asylum seekers (both hereafter referred to as 'asylum seekers') should have non-discriminatory, equitable access to healthcare services, including vaccines, irrespective of their legal status [14-17]. Their right to receive vaccinations in Germany is legally anchored in the Asylum Seekers' Benefit Act [18]. Asylum seekers are accommodated in initial reception centres or collective accommodation centres (both hereafter 


\section{FIGURE 1}

Cases by reporting week and residency status in a large outbreak of measles in Berlin, October 2014-August 2015 (n = $1,344)$

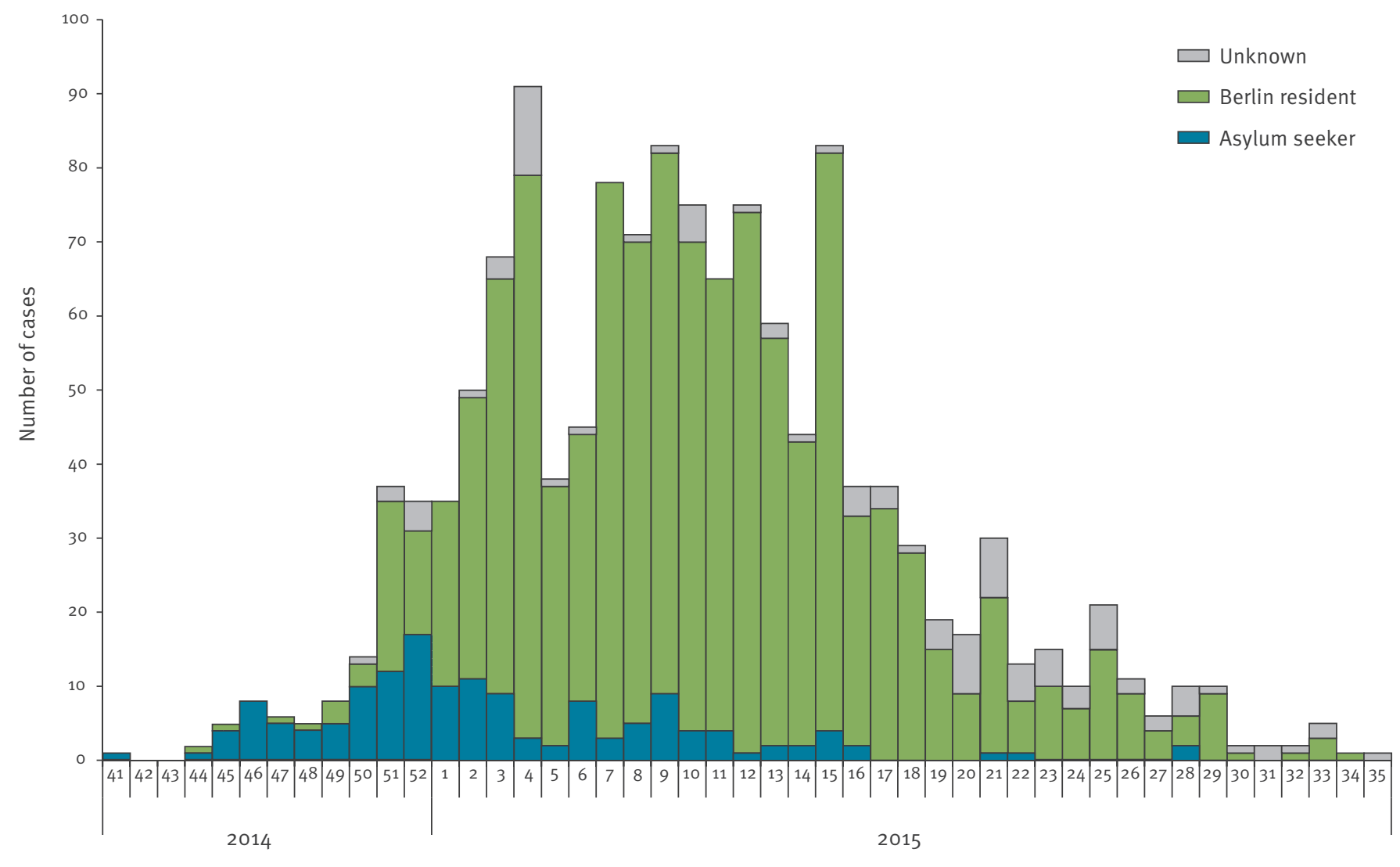

Year and week of notification

referred to as 'asylum seeker homes') upon arrival in Germany. The national recommendation for post-exposure intervention in any community home, including asylum seeker homes, is to vaccinate all persons older than 9 months of age within $72 \mathrm{~h}$ after contact with a measles case [11].

Measles has been notifiable in Germany since 2001. From 2004 to 2013, the annual incidence per million population ranged from 1.5 to 28 without a discernible secular downward trend. During that time, the annual measles incidence was highest in Berlin, driven, in part, by a large outbreak with almost 500 reported cases in 2013. In October 2014, measles cases started to accumulate again in Berlin. Initially, most cases were in asylum seekers. We enhanced epidemiological surveillance of measles, evaluated post-exposure vaccination in homes for asylum seekers, and performed molecular surveillance of MV circulation. This report describes the epidemiological and molecular characteristics of this outbreak.

\section{Methods}

\section{Data sources}

\section{Notification database}

In Germany, clinical suspicion or diagnosis of measles, measles-related death and laboratory detection of measles infection are notifiable to the Local Public Health Authority (LPHA). The surveillance case definition requires that the patient have fever, maculopapular rash and one of the following: cough, coryza, Koplik spots or conjunctivitis, or an epidemiological link to a person with laboratory-confirmed measles infection. Laboratory confirmation was defined as detecting MV nucleic acid by PCR, or MV-specific IgM antibodies or a significant increase in anti-MV IgG. Cases were transmitted to the State Office for Health and Social Affairs (SOHSA) and from there to the federal level public health institute.

\section{Additional case information}

We enhanced epidemiological surveillance of measles cases by requesting that LPHAs systematically collect additional information, including residency status (asylum seeker $(\mathrm{Y} / \mathrm{N}))$, nationality, whereabouts in the two weeks before symptom onset and duration of stay in 


\section{FIGURE 2}

Attack rates per $1,000,000$ by age group among the resident population in a large outbreak of measles in Berlin, October 2014-August 2015

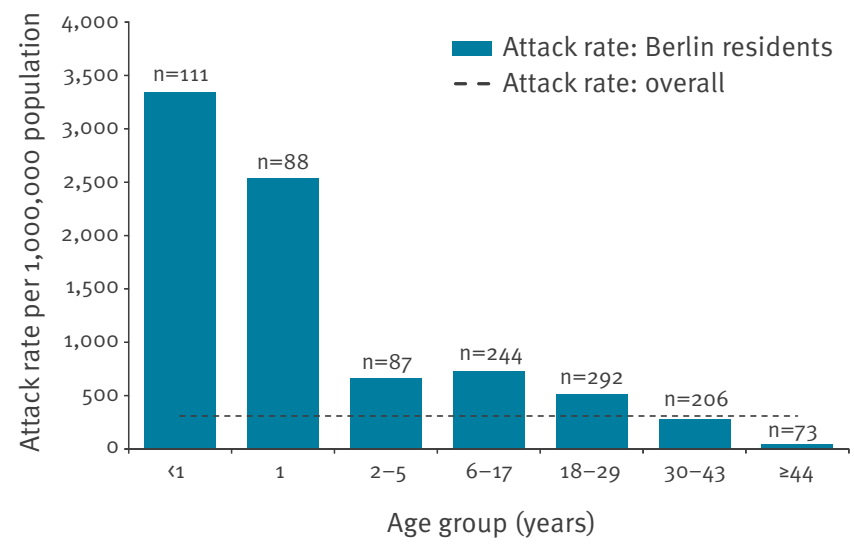

Germany. Information was recorded in a specifically designed Excel sheet and sent to SOHSA.

Molecular data on MV

The National Reference Centre for Measles, Mumps, Rubella (NRC MMR) at the Robert Koch Institute, Berlin, determined the MV genotype in all clinical samples confirmed by detection of viral RNA that were collected in Berlin during the outbreak period. The 'distinct sequence identifier' representing each MV sequence variant was determined and compared using the global WHO Measles Nucleotide Surveillance (MeaNS) database [19]. The phylogenetic tree was constructed using the neighbour-joining algorithm and the p-distance method as implemented in MEGA 7 [20].

For measles cases, we merged information from the notification database with additional case information and molecular data on MV by using the case identifier of the notification system or by date of onset, age, and sex (for molecular data from the NRC MMR).

\section{Epidemiological investigation}

We defined an outbreak case as illness in a person notified with measles in Berlin from 6 October 2014 (week 41) until 30 August 2015 (week 35), if the illness fulfilled the surveillance case definition and was not imported (except for the index patient), and the isolate, if genotyped, belonged to genotype D8. A case was considered to be imported if the patient was abroad during the 7 to 18 days before symptom onset.

We conducted a descriptive analysis of case characteristics by calculating frequencies and proportions or median values and interquartile ranges (IQR) as appropriate. Attack rates per million population, by age group and district, were computed for Berlin resident cases using 2013 population data from the Statistical Office for Berlin-Brandenburg.
Evaluation of post-exposure vaccinations in asylum seeker homes

We evaluated timeliness and completeness of postexposure vaccinations in asylum seeker homes between October 2014 and February 2015. Date of symptom onset and notification of the first case was extracted from the notification system, details on the intervention (e.g. date, number of (eligible) asylum seekers vaccinated/registered) were collected by LPHAs and collated by the SOHSA. We computed median values and IQR of time intervals characterising the timeliness of the intervention. Completeness was assessed only in post-exposure vaccinations targeting all asylum seekers, which excluded homes that had closed living units and interventions restricted to specific vulnerable subgroups, e.g. children or husbands of pregnant women. It was computed as the number of vaccinated asylum seekers divided by the total number of (eligible) registered asylum seekers. Persons older than 9 months of age who were not pregnant and had no clinical signs compatible with measles and no written documentation of two measles vaccinations were eligible.

\section{Molecular investigation}

Suspected measles cases were confirmed in private or hospital laboratories or in the NRC MMR using tests for detection of anti-MV IgM in serum. Alternatively, MV RNA was detected in throat swabs, oral fluid or urine by an accredited PCR test conducted in the NRC MMR. Detected MV was genotyped by sequencing the 450 nucleotides (nt) coding for the C-terminal 150 amino acids of the nucleoprotein and phylogenetic analysis as recommended by the WHO [21]. Representative MV sequence data were submitted to the MeaNS database and to GenBank [19].

\section{Results}

Description of the outbreak

Of 1,359 cases notified during the outbreak period, 15 were considered unrelated to the outbreak; six because of genotypes other than D8 and nine because infection was considered imported, among them three asylum seekers (all from Bosnia and Herzegovina). Thus, 1,344 outbreak cases were ascertained, of which 943 (70\%) were laboratory-confirmed (Table).

Median age of case patients was 17 years (IQR: 4-29 years), 737 (55\%) were male, 345 (26\%) were hospitalised and a 1-year-old child died of measles. In almost two thirds of cases $(64 \%, n=864)$, no link to another measles case was recorded by the LPHAs. Of those with available information $(n=1,258), 86 \%(n=1,086)$ were not vaccinated against measles, 101 (8\%) were vaccinated once, $42(3 \%)$ twice and one case three times (0.2\%) before onset of illness (for 28 (2\%) the number of vaccinations was not recorded).

The index case was a 5-year-old child who travelled with their family from Bosnia and Herzegovina by bus 


\section{FIGURE 3}

Phylogenetic relationship between the measles virus sequence variants detected in a large outbreak of measles in Berlin, August 2014-October $2015(\mathrm{n}=351)$, a large outbreak in Bosnia and Herzegovina (2014-2015) and the World Health Organization Reference and Named Strains for measles virus genotype D8 (marked in grey)

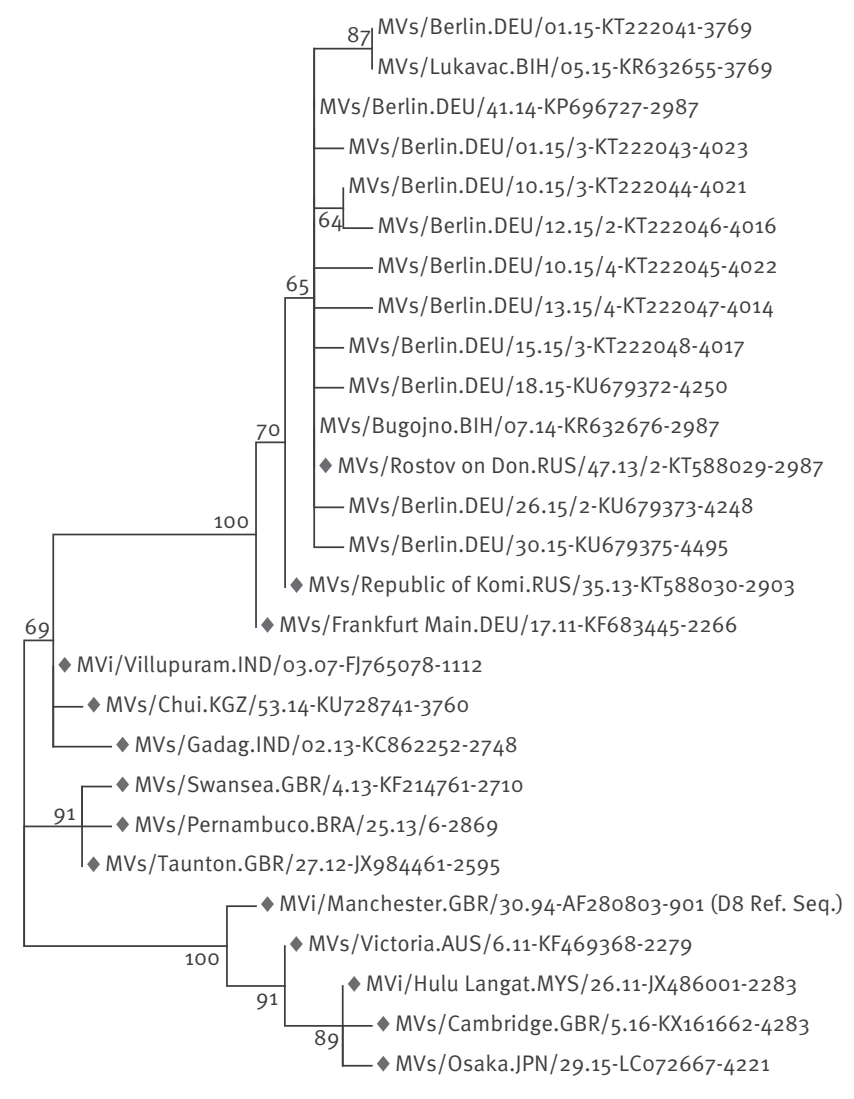

$\stackrel{\longmapsto}{0.005}$

The World Health Organization name, the GenBank accession number (if available) and the 'distinct sequence identifier' used in MeaNS are given for each sequence variant. The phylogenetic analysis is based on the $450-n t$ sequence encoding the C-terminus of the measles virus $\mathrm{N}$ protein. The tree was constructed using the Neighbour-Joining algorithm and the p-distance method as implemented in MEGA7 [20]. Bootstrap values (1,000 replicates) are shown next to the branches. The scale bar indicates a deviation of $5 \mathrm{nt}$ per $1,000 \mathrm{nt}$ sequence.

to Berlin (a ca $24 \mathrm{~h}$ drive) in early October 2014. The child had fever but no rash upon arrival. In the following months, cases occurred predominantly among asylum seekers (Figure 1).

During the outbreak, 146 (11\%) cases occurred in asylum seekers (Table), most of them in children (median age: 5 years, IQR 2-18 years). Overall, 69 (47\%) came from Bosnia and Herzegovina (in 2014: 41/65 cases, $63 \%), 41$ (28\%) from Serbia, eight (6\%) from Syria, the remaining $20 \%$ came from 14 different countries. Measles cases occurred in 35 homes for asylum seekers, located in all Berlin districts, with a median of two cases per asylum seeker home (IQR: 1-5).
By year's end, cases started to accumulate in the Berlin resident population, with a peak in March 2015 (Figure 1). Cases among Berlin residents $(n=1,101)$ occurred in all districts, but the attack rate varied across the 12 districts of Berlin by a factor of almost 3.5 (highest in Neukölln: 546/1,000,000 population, lowest in Steglitz-Zehlendorf: 160/1,000,000 population (citywide incidence: $309 / 1,000,000$ population). Of the Berlin resident cases, almost one third $(n=349,32 \%)$ were linked to other cases in 132 clusters (median number of cases: 2, IQR: 2-3), mostly to household members (253 cases in 106 clusters), meaning that no long transmission chains or sub-outbreaks were observed. Attack rate was highest among «1 year olds $(3,334 / 1,000,000$, Figure 2) followed by 1 year-olds $(2,538 / 1,000,000$, which together accounted for $18 \%$ of Berlin's resident cases. The majority of cases were in adults $(n=571,52 \%)$, most of whom $(498 / 571,87 \%)$ were born after 1970 .

\section{Evaluation of post-exposure vaccinations in asylum seeker homes}

In the study period, cases were ascertained in 32 asylum seeker homes. Case-patients' median age in clusters in asylum seeker homes was 4 years (IQR: 1-18.5 years). Of 32 asylum seeker homes, we received no detailed information for seven homes, and in a further seven homes no post-exposure intervention was performed for different reasons (e.g. lack of resources). In the remaining 18 homes, post-exposure vaccinations were conducted with a median time interval from symptom onset of the first case to vaccination of 7.5 days (IQR: 6-10 days); in three homes vaccination occurred within the recommended $72 \mathrm{~h}$ after detection of measles with no further cases notified during the following 18 days. In the remaining 15 homes, 16 cases were notified during this time period. Median time interval between (i) symptom onset of the first case and notification and (ii) notification and post-exposure vaccination was 4 days (IQR: $3-8$ days) and 2 days (IQR: 0-6 days), respectively.

In the eight asylum seeker homes where vaccination was offered to all inhabitants and denominator data were available, 1,133/2,390 (47\%) were reached. In five of these homes, eligibility criteria for vaccination were also recorded; there, 706/1,344 (53\%) were reached.

\section{Molecular investigation}

During the outbreak period, the NRC received samples from 587 suspected cases. MV genome was detected in samples from 415 laboratory-confirmed cases and the MV genotype was determined for 359 cases of which 354 showed a wild-type virus. Of the 351 cases associated with genotype D8, 306 showed the predominant sequence variant Named Strain MVs/Rostov on Don. RUS/47.13/2, hereafter referred to as 'D8-Rostov-Don'. This variant was detected in Berlin during the entire outbreak period and had previously been found during a large outbreak in Bosnia and Herzegovina (February 2014 to April 2015). Forty-five cases had variants 
Measles virus sequence variants (given by the 'distinct sequence identifier') by reporting week of cases in a large outbreak in Berlin, October 2014-August $2015(\mathrm{n}=322)$

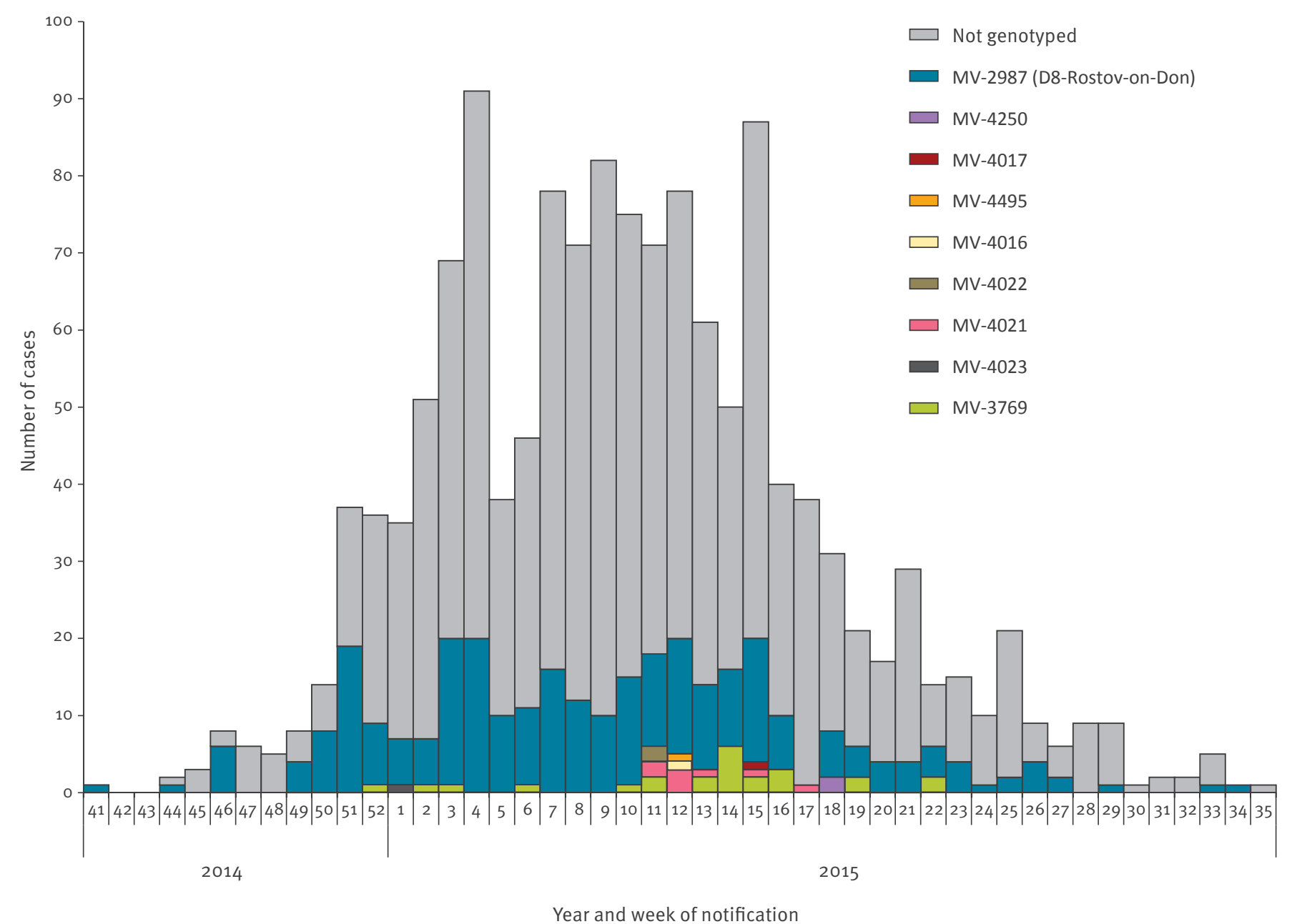

deviating in the $450 \mathrm{nt}$ region by $1-2 \mathrm{nt}$ from D8-RostovDon (10 variants, Figure 3) [22]. One variant detected in Berlin from December 2014 to May 2015 (MVs/Berlin. DEU/01.15) was also found in the course of the aforementioned outbreak (MVs/Lukavac.BIH/05.15) [22].

We were able to match 322 laboratory-confirmed cases with MV genotype D8 to notified outbreak cases (254 Berlin residents and 46 asylum seekers and in 22 with unknown residency status), of which 282 (88\%) had the variant D8-Rostov-Don and 40 (12\%) had a 1-2 nt deviating variant (Figure 4), 11 asylum seekers, 28 Berlin residents, one case with unknown residency status. None of these cases had a travel history during their period of infection. Of these 40 cases, 24 shared an identical variant (MVs/Lukavac.BIH/05.15). The first of these cases had a symptom onset on 20 December 2014 and the last on 21 May 2015.

\section{Discussion}

In this large outbreak, MV was likely introduced by and initially spread among asylum seekers before affecting the resident population of Berlin, which ultimately accounted for the vast majority of cases. Among Berlin's resident population, all age groups eligible for vaccination were affected, with the highest attack rate in children under 2 years of age. More than half of the cases were in adults, most of whom were born after 1970, the age group for which STIKO recommends measles vaccination if vaccination history is incomplete or unknown. Interventions of LPHAs in homes for asylum seekers were mostly outside the recommended $72 \mathrm{~h}$ time window, reached only half of the potential contacts and apparently did not halt the outbreak. Continuous genotyping throughout the outbreak period demonstrated almost endemic (i.e. $\geq 12$ months) transmission of the predominant variant D8-Rostov-Don in Berlin.

Several lines of evidence indicate that measles was introduced by and initially spread among asylum seekers: firstly, the index case occurred in an asylum seeker who had symptoms upon arrival in Berlin, after travelling from Bosnia and Herzegovina where a large measles outbreak was ongoing at that time [22]. Subsequent cases occurred predominantly among asylum seekers (often from Bosnia and Herzegovina) that 
Case characteristics in a large outbreak of measles in Berlin, October 2014-August $2015(\mathrm{n}=1,344)$

\begin{tabular}{|c|c|c|c|c|c|c|c|c|}
\hline \multirow{2}{*}{ Characteristics } & \multicolumn{2}{|c|}{ Berlin resident } & \multicolumn{2}{|c|}{ Asylum seeker } & \multicolumn{2}{|c|}{ Unknown } & \multicolumn{2}{|c|}{ Total } \\
\hline & $\mathrm{n}$ & $\%$ & $\mathrm{n}$ & $\%$ & $\mathrm{n}$ & $\%$ & $\mathrm{n}$ & $\%$ \\
\hline Number of cases & 1,101 & 100 & 146 & 100 & 97 & 100 & 1,344 & 100 \\
\hline Male & 612 & 55.6 & 76 & 52.0 & 49 & 50.5 & 737 & 54.8 \\
\hline Laboratory-confirmed & 777 & 70.6 & 99 & 67.8 & 67 & 69.1 & 943 & 70.2 \\
\hline In clusters & 349 & 31.7 & 107 & 73.3 & 24 & 24.7 & 480 & 35.7 \\
\hline Unvaccinated a $^{\text {a }}$ & 888 & 85.2 & 127 & 94.1 & 71 & 87.6 & 1,086 & 86.3 \\
\hline Hospitalised $^{\mathrm{b}}$ & 265 & 24.1 & 35 & 24.0 & 45 & 46.9 & 345 & 25.7 \\
\hline \multirow[t]{2}{*}{ Death } & 1 & 0.1 & 0 & 0 & 0 & 0 & 1 & 0.1 \\
\hline & Median & IQR & Median & IQR & Median & IQR & Median & IQR \\
\hline Age (years) & 18 & $5-30$ & 5 & $2-18$ & 21 & $9-29$ & 17 & 4-29 \\
\hline
\end{tabular}

IQR: interquartile range.

a Information was available for 1,258 cases on vaccination status; 1,042 Berlin residents, 135 asylum seekers, 81 unknown.

${ }^{\mathrm{b}}$ Information was available for 1,342 on hospitalisation status; 1,100 Berlin residents, 146 asylum-seekers, 96 unknown.

acquired infection in Berlin. Secondly, genotyping data indicate sequence identity of $M V$ isolated from the index case, the large majority of the following cases in Berlin, and cases of the concurrent outbreak in Bosnia and Herzegovina. Thirdly, despite of continuous monitoring of circulating MV variants, the main variant D8-Rostov-Don and closely related variants had never been found in Berlin before.

Population immunity in Berlin was too low to prevent city-wide measles spread across all age groups, equating to insufficient vaccine coverage. School-entry examinations document that coverage with two doses of a MV-containing vaccine has been consistently below $95 \%$ in Berlin, although there has been a strong increase over the past 15 years (from $21 \%$ in 1998-2001 to $92 \%$ in 2014) $[10,23]$. Age-dependent differences in vaccine coverage were observed in a national population survey from 2008 to 2011; coverage (1 dose) was lower in older age groups (80\% in $18-29$ year olds; $47 \%$ in 30-39 year olds) [24]. Taken together, population immunity likely decreases in Germany with increasing age, until age groups born before 1970 .

The majority of cases were in adults. Of note, there is a clear shift towards adult measles cases in German notification data (from $11 \%$ in 2003 to $43 \%$ in 2013) [25], in the absence of a noticeable downward trend in measles notification rates over the past 10 years in Germany. Furthermore, under-reporting of measles in Germany is highest in adults [26]. Consequently, their involvement in this outbreak (and in measles epidemiology in Germany in general) can be assumed to be disproportionately underestimated and the difference in attack rates between adults and children in this outbreak is likely offset, at least partially. Interestingly, standard inquiries of cases in this outbreak by LPHAs revealed that adults tended to be ignorant of their vaccination status rather than sceptical of vaccines, suggesting they could be successfully targeted in catch-up campaigns (not yet conducted in Berlin or elsewhere in Germany) [27].

Post-exposure vaccination by LPHAs to prevent onward transmission in homes for asylum seekers were not always conducted and, where conducted, reached only half of the potential contacts. Additionally, most (83\%) vaccination measures occurred after the recommended $72 \mathrm{~h}$ window, mainly because LPHAs were not notified in a timely fashion (vaccinating after $72 \mathrm{~h}$ may still be useful, e.g. to prevent tertiary cases). We did not systematically assess the reasons for delayed case notification. Anecdotally, not all cases sought medical attention immediately and sometimes the first notified case was initially misdiagnosed with a disease other than measles. Furthermore, the large number of asylum seekers in some homes often exceeded the response capacity of the LPHAs. Taken together, timely vaccination of all contacts proved challenging in these settings where LPHA often became aware of measles too late, potential contacts were often difficult to reach and large in number, and language barriers complicated intervention logistics. Of note, clusters occurred in many homes for asylum seekers (mostly involving children), but were small in size (median of two cases). This indicates a fairly high vaccination coverage among inhabitants as has been shown for migrating populations in other settings, an effect of post-exposure vaccinations, or both $[28,29]$. Targeting, or at least prioritising, vulnerable groups (e.g. children) in postexposure vaccinations in (mass) asylum seeker homes should be considered, particularly in crisis situations.

It remains unclear why the outbreak became so large and long-lasting. Frequent introduction of the outbreak virus by different asylum seekers may seem an obvious explanation, but the limited available epidemiological and molecular information lends little support 
to this hypothesis. Only three measles cases among asylum seekers (all from Bosnia and Herzegovina) were considered imported. Yet, under-ascertainment of measles cases is likely, particularly at the start of the outbreak (e.g. there is a gap of $>3$ weeks in onset dates between the index and subsequent cases). The identification of various outbreak variants is not necessarily indicative of imported MV. All variants were closely related to the main outbreak variant D8-RostovDon. Most were detected only once or over a short period, and their occurrence scattered around the (virus-number) peak of the outbreak, which is compatible with random mutations of the virus. Furthermore, detection of a variant probably descending from the outbreak main variant has previously been observed in a large outbreak, in which multiple importations were deemed unlikely [30]. In keeping with that pattern, none of the (matched) cases infected with an outbreak variant deviating from the main variant were imported. However, the predominant and the second most variant identified in Berlin were also detected in the outbreak in Bosnia and Herzegovina, indicating at least two virological links to the parallel outbreak. Notwithstanding, our molecular analysis was restricted to $450 \mathrm{nt}$ of the MV N gene, and therefore does not allow the monitoring of sequence variation in other regions of the viral genome. Establishing whole genome sequencing in outbreak situations across Europe might provide more detailed information. More important, however, is a continuous monitoring of virus variants during the whole outbreak period, especially when considering increasing population movement in recent years.

Enhancing the surveillance of notified measles cases, including routinely collecting information on residency status, and MV genotyping, were pivotal in understanding the epidemiology of this outbreak. Since October 2015, residency status and accompanying information have been routinely collected on all notifiable diseases in Germany. Although the data need to be interpreted with caution, they indicate that most notified infectious diseases in asylum seekers are vaccine-preventable (predominantly varicella zoster infections), and most are acquired within Germany (data not shown). This underlines the vulnerability of this group for vaccinepreventable diseases.

No city-wide system for offering vaccinations to asylum seekers was in place during the outbreak period. Since September 2015, Berlin has offered immunisation with MV- (and polio-) containing vaccines, as recommended by WHO, the European Centre for Disease Prevention and Control and STIKO, to all asylum seekers in Berlin $[31,32]$. Coupled with a brief medical examination, this has become an integral part of the asylum seekers' registration process since March 2016 in Berlin. Notwithstanding, there remains a continued risk of importation of MV as many residents travel and many travellers arrive. In 2014, 12.4 million people visited Berlin, of which 4.8 million came from abroad (one fifth of all foreign visitors to Germany) [33]. In conjunction with insufficient population immunity, eliminating measles in Berlin is likely to remain a distant prospect in the absence of supplementary immunisation activities.

\section{Conclusion}

This outbreak exemplifies why, in addition to ethical and legal grounds, asylum seekers should be timely offered vaccination against measles: to protect them. In addition, catch-up campaigns to close immunisation gaps, particularly in adults, are urgently needed in Berlin's resident population. Surveillance of infectious diseases should routinely collect information on residency status to be able to assess and quickly respond to infectious disease risks in asylum seekers. MV genotyping throughout the outbreak period demonstrated continuous circulation of variant D8-Rostov-Don for almost 11 months in Berlin.

\section{Acknowledgements}

We are indebted to the 12 local public health authorities in Berlin for their diligent and committed work and collaboration in this outbreak.

No funding was received related to the work in this manuscript.

\section{Conflict of interest}

None declared.

\section{Authors' contributions}

DW contributed to data collection, data analysis, data interpretation and drafting the manuscript.

AH contributed to literature search, data collection, data analysis, data interpretation, creating graphics and drafting the manuscript.

AM contributed to molecular-biological investigation. SS contributed to molecular-biological investigation and creating graphics.

DS contributed to data collection and data interpretation.

References

1. Perry RT, Murray JS, Gacic-Dobo M, Dabbagh A, Mulders $M N$, Strebel PM, et al. Progress toward regional measles elimination - worldwide, 2000-2014. MMWR Morb Mortal Wkly Rep. 2015;64(44):1246-51. DOI: 10.15585/mmwr.6444a4 PMID: 26562349

2. Mina MJ, Metcalf CJE, de Swart RL, Osterhaus ADME, Grenfell BT. Long-term measles-induced immunomodulation increases overall childhood infectious disease mortality.Science. 2015;348(6235):694-9. DOI: 10.1126/science.aaa3662 PMID 25954009

3. Bundesministerium für Gesundheit. [Federal Ministry of Health]. Nationaler Aktionsplan 2015-2020 zur Elimination der Masern und Röteln in Deutschland: Hintergründe, Ziele und Strategien. [National action plan 2015-2020 for the elimination of measles and rubella in Germany: Background, goals and strategies]. Berlin: Federal Ministry of Health; [Accessed 13 Feb 2017]. German. Available from: https://www.gmkonline.de/ documents/Aktionsplan_Masern_Roeteln_2.pdf

4. World Health Organization Regional Office for Europe (WHO Europe). Eliminating measles and rubella and preventing 
congenital rubella infection: WHO European Region strategic plan 2005-2010. Copenhagen: WHO Europe; 2005. [Accessed 9 Feb 2017]. Available from: http://www.euro.who.int/_data/ assets/pdf_file/ooo8/79028/E87772.pdf

5. World Health Organization Regional Office for Europe (WHO Europe). Eliminating measles and rubella: Framework for the verification process in the WHO European Region. Copenhagen: WHO Europe; 2014. [Accessed 23 Nov 2015]. Available from: http://www.euro.who.int/_data/assets/ pdf_file/oo09/247356/Eliminating-measles-and-rubellaFramework-for-the-verification-process-in-the-WHO-EuropeanRegion.pdf

6. Clemmons NS, Gastanaduy PA, Fiebelkorn AP, Redd SB, Wallace GS. Measles - United States, January 4-April 2, 2015. MMWR Morb Mortal Wkly Rep. 2015;64(14):373-6.PMID: 25879894

7. Papania MJ, Wallace GS, Rota PA, Icenogle JP, Fiebelkorn AP, Armstrong GL, et al. Elimination of endemic measles, rubella, and congenital rubella syndrome from the Western hemisphere: the US experience. JAMA Pediatr. 2014;168(2):148-55. DOI: 10.1001/jamapediatrics.2013.4342 PMID: 24311021

8. World Health Organization (WHO). Global measles and rubella strategic plan: 2012-2020. Geneva: WHO; [Accessed 9 Feb 2017]. Available from: http://apps.who.int/iris/ bitstream/10665/44855/1/9789241503396_eng.pdf.

9. Robert Koch-Institut (RKI). Empfehlungen der Ständigen Impfkommission (STIKO) am RKI. [Recommendations of the German Standing Committee on Vaccination (STIKO) at the RKI]. Epidemiologisches Bulletin. Berlin: RKI; 29 Aug 2016. German. Available from: https://www.rki.de/DE/ Content/Infekt/EpidBull/Archiv/2016/Ausgaben/34_16. pdf?__blob=publicationFile

10. Robert Koch-Institut (RKI). Impfquoten bei der Schuleingangsuntersuchung in Deutschland 2014. [Vaccine coverage at school entry examination in Germany in 2014]. Berlin: RKI; 25 Apr 2016. German. Available from: https:// www.rki.de/DE/Content/Infekt/EpidBull/Archiv/2016/ Ausgaben/16_16.pdf?_blob=publicationFile

11. Robert Koch-Institut (RKI). Mitteilung der Ständigen Impfkommission (STIKO) am Robert Koch-Institut (RKI). [Information of the German Standing Committee on Vaccination (STIKO) at the RKI]. Berlin: RKI; 16 Aug 2010. German. Available from: https://www.rki.de/DE/Content/Infekt/EpidBull/ Archiv/2010/Ausgaben/32_10.pdf?_blob=publicationFile.

12. Eurostat. Database: Asylum and managed migration (migr). Luxembourg: Eurostat; [Accessed 1 Aug 2017]. Available from: http://ec.europa.eu/eurostat/data/database?node_code=migr

13. Amt für Statistik Berlin-Brandenburg. [Office for Statistics Berlin-Brandenburg]. Statistiken. [Statistics]. Berlin: Office for Statistics Berlin Brandenburg; [Accessed 13 Feb 2017]. German. Available from: https://www.statistik-berlin-brandenburg.de/ Statistiken/inhalt-statistiken.asp

14. World Health Organization Regional Office for Europe (WHO Europe). Health2020: A European policy framework and strategy for the 21st century. Copenhagen: WHO Europe; 2013. [Accessed 9 Feb 2017]. Available from: http://www.euro.who. int/_data/assets/pdf_file/0011/199532/Health2020-Long. pdf? $\overline{\text { ua }=1}$

15. Weis P. The Convention Relating to the Status of Stateless Persons.Int Comp Law Q. 1961;10(10(2)):255-64. DOI: 10.1093/ iclqaj/10.2.255

16. Declaration of Alma-Ata. Lancet. 1979;1(8109):217-8. PMID: 84242

17. World Health Organization (WHO). Sixty-First World Health Assembly. Geneva, 19-24 May 2008. Geneva: WHO; [Accessed 9 Feb 2017]. Available from: http://apps.who.int/gb/ebwha/ pdf_files/WHA61-REC1/A61_REC1-en.pdf

18. Federal Ministry of Justice. Asylbewerberleistungsgesetz. [Asylum Seekers' Benefit Act]. Bonn: Bundesgesetzblatt (BGBI). I S. 2541. 17 Jul 2017. [Accessed 31 Jul 2017]. Available from: http://www.gesetze-im-internet.de/bundesrecht/ asylblg/gesamt.pdf

19. Rota PA, Brown K, Mankertz A, Santibanez S, Shulga S, Muller $C P$, et al. Global distribution of measles genotypes and measles molecular epidemiology. J Infect Dis. 2011;204(Suppl 1):S514-23. DOI: 10.1093/infdis/jir118 PMID: 21666208

20. Kumar S, Stecher G, Tamura K. MEGA7: Molecular Evolutionary Genetics Analysis Version 7.0 for Bigger Datasets. Mol Biol Evol. 2016;33(7):1870-4. DOI: 10.1093/molbev/msw054 PMID: 27004904

21. World Health Organization (WHO). Measles virus nomenclature update: 2012.Wkly Epidemiol Rec. 2012;87(9):73-81.PMID: 22462199

22. Salimović-Bešić I, Šeremet M, Hübschen JM, Hukić M, Tihić N, Ahmetagić S, et al. Epidemiologic and laboratory surveillance of the measles outbreak in the Federation of Bosnia and Herzegovina, February 2014-April 2015. Clin Microbiol Infect. 2016;22(6):563.e1-7. DOI: 10.1016/j.cmi.2016.02.005 PMID: 26928202

23. Robert Koch-Institut (RKI). Impfraten deutscher Kinder bei der Schuleingangsuntersuchung im Jahr 2002. [Vaccine coverage of German children at school entry examination in the year 2002]. Epidemiologisches Bulletin. Berlin: RKI; 30 Apr 2003. German. Available from: http://edoc.rki.de/documents/rki_fv/ rePoSwYQt9oyc/PDF/24xNoiiVGsOc.pdf

24. Poethko-Müller C, Schmitz R. Impfstatus von Erwachsenen in Deutschland: Ergebnisse der Studie zur Gesundheit Erwachsener in Deutschland (DEGS1). [Vaccination coverage in German adults: results of the German Health Interview and Examination Survey for Adults (DEGS1)].Bundesgesundheitsblatt Gesundheitsforschung Gesundheitsschutz. 2013;56(5-6):845-57. DOI: 10.1007/s00103013-1693-6 PMID: 23703506

25. Robert Koch-Institut (RKI).SurvStat@RKI 2.0. Berlin: RKI; [Accessed 9 Feb 2017]. Available from: https://survstat.rki.de/ Content/Query/Create.aspx

26. Takla A, Wichmann O, Rieck T, Matysiak-Klose D. Measles incidence and reporting trends in Germany, 2007-2011. Bull World Health Organ. 2014;92(10):742-9. DOI: 10.2471/ BLT.13.135145 PMID: 25378728

27. Hoffmann A, Sagebiel D, Hentschel K, Werber D. Large measles outbreak in Berlin 2014/2015 - Many cases not opposed to vaccination, yet unvaccinated (reference number 3048). In: European Scientific Conference on Applied Infectious Disease Epidemiology (ESCAIDE). Abstract Book; 1-13 Nov 2015; Stockholm, Sweden. Stockholm: ESCAIDE;2015. [Accessed 12 Dec 2016]. p. 58. Available from: http://www.escaide.eu/sites/ escaide/files/documents/escaide-2015-abstract-book.pdf

28. Barnett ED, Christiansen D, Figueira M. Seroprevalence of measles, rubella, and varicella in refugees.Clin Infect Dis. 2002;35(4):403-8. DOI: 10.1086/341772 PMID: 12145723

29. Greenaway C, Dongier P, Boivin J-F, Tapiero B, Miller M, Schwartzman K. Susceptibility to measles, mumps, and rubella in newly arrived adult immigrants and refugees.Ann Intern Med. 2007;146(1):20-4. DOI: 10.7326/0003-4819-146-1200701020-00005 PMID: 17200218

30. Mankertz A, Mihneva Z, Gold H, Baumgarte S, Baillot A, Helble $R$, et al. Spread of measles virus D4-Hamburg, Europe, 20082011. Emerg Infect Dis. 2011;17(8):1396-401. DOI: 10.3201/ eid1708.101994 PMID: 21801615

31. World Health Organization Regional Office for Europe (WHO Europe). WHO-UNHCR-UNICEF joint technical guidance: general principles of vaccination of refugees, asylum-seekers and migrants in the WHO European Region. Copenhagen: WHO Europe; 23 Nov 2015. Available from: http://www.euro.who. int/en/health-topics/health-determinants/migration-andhealth/news/news/2015/11/who,-unicef-and-unhcr-call-forequitable-access-to-vaccines-for-refugees-and-migrants/ who-unhcr-unicef-joint-technical-guidance-general-principlesof-vaccination-of-refugees,-asylum-seekers-and-migrants-inthe-who-european-region

32. European Centre for Disease Prevention and Control (ECDC). Rapid Risk Assessment. Communicable disease risks associated with the movement of refugees in Europe during the winter season. Stockholm: ECDC; 10 Nov 2015. Available from: http://ecdc.europa.eu/en/publications/Publications/refugeemigrant-health-in-european-winter-rapid-risk-assessment.pdf

33. Amt für Statistik Berlin-Brandenburg. [Office for Statistics Berlin-Brandenburg]. Tourismus Basisdaten. [Tourism. Basic data]. Berlin: Office for Statistics Berlin-Brandenburg; [Accessed 9 Feb 2017]. Available from: https://www.statistikberlin-brandenburg.de/BasisZeitreiheGrafik/Bas-Tourismus.as p?Ptyp $=300 \&$ Sageb $=45005 \&$ creg $=$ BBB \&anzwer $=7$

\section{License and copyright}

This is an open-access article distributed under the terms of the Creative Commons Attribution (CC BY 4.0) Licence. You may share and adapt the material, but must give appropriate credit to the source, provide a link to the licence, and indicate if changes were made.

This article is copyright of the authors, 2017. 